\title{
Survey of Scientific and Technical Communication in Mexico, Central America, Panama, and Colombia ${ }^{1}$
}

Mr. Shaw is librarian, U.S. Department of Agriculture.

Conferences with many scientists and $\checkmark$ observation of scientific library research resources indicate with inescapable force that the development of scientific research in the tropics is seriously hampered by lack of scientific communication.

A scientist who has no way of learning of developments in his field falls so far behind in a few years that he cannot contribute to the development of his science. Improvement in scientific communication is, therefore, an essential prerequisite for an effective program for advancing scientific and technical research in the tropics. So long as scientific communication remains at its present low level, much of the money invested in training scientists and in equipping laboratories will be wasted.

The Inter-American Institute of Agricultural Sciences is in a position to experiment with methods for improving scientific communication. Its own needs and the needs of scientists throughout cooperating countries are close enough together so that if the institute is adequately equipped to supply its own staff with scientific information, it can with very little more effort ensure better communication among all scientists. If the institute does not assume this responsibility, and there appears to be no other in-

${ }^{1}$ Part of a more extensive report made by Mr. Shaw. stitution which could perform this function adequately over the whole range of agriculture and the sciences which underly it, the students graduating from the institute will be subject to the same discouragement, through lack of intellectual equipment, that now plagues all the scientists in the countries visited.

An adequate communication service would require capital investment of some $\$ 30,000$ plus a program of service at about three times the amount now spent for library, abstracting, and publishing by the institute. In view of the expanding program of the institute, it would appear likely that in the course of eight or Io years the amount recommended for current operation would not be a disproportionate share of the institute's income. However, the need for publishing, abstracting, bibliographic and copying services is urgent and it is therefore recommended that the institute make every effort to obtain additional funds, outside of country quotas, for the next eight or Io years in order to start immediately on a program of experimentation in the improvement of scientific communication.

Such a regional program might well set a pattern for future library development in large areas of the world and it should be considered an experimental program with emphasis on techniques of communication rather than merely expansion of the institute's own library services. It is recom- 
mended that regardless of whether additional funds are obtained for this purpose the institute should give this program of improvement of communication top priority, and should do everything it possibly can to carry out this program as the only means of ensuring continuing usefulness of the training and research work done not only at the institute, but also through the national educational institutions of each country and by fellowship grants.

\section{Objectives}

The report which follows covers a survey of the scientific and technical library research potential of Mexico, the Central American countries, Panama, and Colombia. This study was intended to determine: I) what research library services exist; 2) the literature needs of agricultural research workers; and 3) the possible methods by which research needs can be met within funds which may possibly be available.

\section{Importance of the Problem}

The need for literature as a basis for research is well recognized by working scientists all over the world. The relative scarcity of such materials in the countries visited has been recognized and the InterAmerican Institute of Agricultural Sciences as well as other institutions have been attempting for some time to devise plans under which it might be possible for any scientist working in the field of agriculture or its underlying sciences to have access to the recorded work of other scientists of all times and places, to the full extent to which such literature is needed for effective research.

As stated in the report of the Royal Society Scientific Information Conference ${ }^{2}$

"If it is agreed that the advancement of science rests primarily upon the genius of each scientist in his laboratory, whether that

${ }^{2}$ Science 108:151, Aug. 13, 1948. laboratory be in a great center of research or in an isolated corner of the world, and that each scientist, no matter where he may be, must profit from the work of his colleagues, all over the world and of all times, then it must follow that anything which contributes to the freedom and ease of communication among scientists is, per se a contribution to science."

Viewed in this framework of scientific communication this study does not concern itself to any great extent with the normal routines and techniques of library housekeeping but, rather, concentrates on the major problem of the needs of science and the possible application of the various means of communication among scientists, including study of the parts of the problem of publishing, abstracting, indexing, bibliographical services, and scientific aids such as photographic reproduction.

\section{Method of Investigation}

In the course of this survey some 80 libraries of various types were visited in Mexico, Guatemala, Salvador, Honduras, Nicaragua, Costa Rica, Panama, and Colombia. In addition the needs and available resources were discussed with more than 200 scientists and research and extension workers in institutions of various types, including private and public research institutions, and including many institutions which are not primarily agricultural in nature.

In view of the fact that the sciences which underlie agriculture, such as chemistry, biology and zoology, are basic to medical research as well, all medical libraries known to exist in these countries were visited as well as the agricultural scientific, technical, university, and other scholarly institutions.

In addition to appraising the total content of each library, special attention was paid to the number of scientific journals on file and the types of scientific journals available. In each case scientists who depended 
upon a particular library were questioned about the availability of the basic abstracting and indexing journals in the field, and also about the percentage of materials listed in the abstracting journals which they could obtain. In each case scientists were asked to discuss problems of production and distribution of scientific literature in their own countries, as well as problems of abstracting and use of photographic copies.

\section{Summary of Results}

Of all the libraries visited, not more than four could be considered good quick-reference or working collections for the scientist or technologist. These include the Sección de Investigaciones Especiales in Mexico City, which has a strong collection of journals for the limited fields which it attempts to cover, the library of the Inter-American Institute of Agricultural Sciences at Turrialba, the library of the Facultad de Agronomía at Medellin, and the highly specialized geophysical collection of the Instituto Geofísico de Los Andes at Bogotá.

There were many libraries visited which were larger than these, and there is much material of historical value or taxonomic value in other institutions, but it can be said that no place in the countries visited had really adequate working collections, and it is doubtful, even if all of the libraries visited could pool their resources through a cooperative scheme, that the potential for research service would approximate as much as 15 or 20 per cent of what might be found in current abstracting journals on any given subject.

Conferences with scientists indicated almost invariably that they rarely had access to as much as 5 or 6 per cent of the literature which they might find listed on any subject in a pertinent abstracting journal, and the highest estimate offered by anyone was Io per cent.
The administrators of research and research workers in the countries visited all agree that it is not possible to do research above the high school level without bibliographical resources, and all agree that minimum bibliographical resources are not available. Thus, something must be done to improve scientific communication in the countries visited or it would appear that the investments made by various governments and agencies in their own and in cooperative research programs can not be as fruitful as they should be.

\section{Possible Approaches to Improvement of Scientific Communication}

There are a number of services now available which could, if properly exploited, improve scientific communication in Latin America. Among these are the bibliographical and microfilm services provided by American institutions, such as the Army Medical Library and the United States Department of Agriculture Library.

The fundamental requirements for improvement of research potential are:

I. There must be some way by which any scientist, no matter where he works, may find out what is being published currently and what has been published that will help him do his own particular job.

2. There must be some means by which pertinent material can be obtained by any scientist as needed in connection with his research or program work.

3. Each scientist must have at hand the materials which he uses more or less constantly.

4. There must be adequate means for making known the results of research currently as the research is completed, by publishing, auxiliary publication, or similar techniques.

There are many different possible approaches to these problems. One of the 
approaches would be for each country to attempt to build up its own collection of literature and services so as to meet its own needs completely. In view of the fact that there are some 16,000 journals currently published which contain material of importance to agriculture it does not appear feasible, at least for the smaller countries, ever to plan to duplicate the world's great research libraries in these fields. Even if they should succeed in any of these countries in building up a complete library in the field of agriculture, there would still be the problem of serving scientists other than those at the center where the research library is developed. It would appear, therefore, that regardless of the extent to which each country may succeed in building up its own collections (points $\mathrm{I}$ and 2 above) i.e., letting the scientist know what exists and getting copies to him, will still be factors which determine whether the individual scientist who has to work at a point other than a great research center can obtain what he must have in order to perform effective work.

It is interesting to note that not a single one of the countries visited has, at the present time, a complete collection of its own output in the field of agriculture. It would appear that the emerging group of scientists who realize the need for effective literature services has been too small in any of the countries, with the possible exception of Colombia, to cause any effective action or even planning toward provision of this minimum collection of the printed output of their own country.

As will be noted in the discussion of techniques which follows, it does not appear feasible to utilize photographic techniques in each institution in each of the small countries because of the limited amount of material which they have available to copy and the resultant high cost of such services and waste of materials. It does not appear feasible either to obtain agreement on the part of all countries as to a single center from which they are to obtain the needed services. It would appear, therefore, that the only feasible solution would be to establish the services which all scientists in the Americas agree are essential if they are to do productive work at a single inter-American institution such as the Inter-American Institute of Agricultural Sciences at Turrialba, and to start providing the required services in a few agricultural fields which are of general interest in all of the American countries, letting the service grow as funds permit and as demands grow. In developing this service two other feasible centers in addition to Turrialba might be the Sección de Investigaciones Especiales, Ministerio de Agricultura, library in Mexico City $^{3}$ and if agreement among scientists and scientific institutions could be effected in Colombia, at some place in Colombia. As noted above, this does not represent any consensus of opinion but rather a pragmatic approach to improvement of scientific communication in an area in which workers are fairly widely dispersed, library facilities are exceedingly limited and widely dispersed, and the total research potential is so low at all points, and funds available are so limited at all points, that there appears to be no practical approach to increasing the research potential at all institutions to a satisfactory level.

\section{General Problems}

In the matter of providing library and bibliographical services, as in all other cultural measures, there are several problems of real importance despite the fact that they are mechanical. Probably the greatest problem in this field is that of international currency exchange restrictions. Because

\footnotetext{
In cooperation with the Rockefeller Foundation.
} 
each transaction requires approximately the same amount of red tape in obtaining dollars, the 50 to $\$ 5.00$ transaction involved in obtaining scientific literature is just as difficult as obtaining $\$ 1000$ in foreign exchange for the purchase of a major piece of equipment. For this reason, at a number of points it was found that valuable equipment was idle for the lack of a small part or for the lack of supplies which has to be purchased in petty cash amounts, because of the lack of dollars.

The second general problem is that the volume of work at each place in each country is too little to justify either adequate installations of equipment or purchase of supplies in quantities that are economical. For example, if it were decided to install a camera for producing microfilm at a growing and important institution such as the Agricultural Experiment Station at Palmira or the Facultad de Agronomía at Medellin, since each of these institutions has so little material that would be copied, the date on the roll of photostat paper would expire before even a fraction of the paper was used. It would thus be necessary to obtain supplies in very small specialized quantities and much of the supplies thus obtained would spoil before they were used. It would appear, therefore, that because of exchange restrictions and because of volume of work the question of supplies is really a more critical one in the area of scientific communication than is the question of basic equipment. This is another reason why there appears to be more promise in centralized service under an international organization, or in cooperation with one of the North American foundations, rather than through a large number of small installations. Utilization of a central installation which is international in character would solve the problem of obtaining supplies, both because the international institution would not have the dollar problem and because the volume of use might be sufficient to make possible economic operation.

\section{General Discussion of Library Facilities Observed}

\section{Mexico:}

The libraries visited in Mexico City included the very good working collection of the Sección de Investigaciones Especiales, the Biblioteca Benjamín Franklin, the Biblioteca de la Dirección de Agricultura, the Biblioteca de la Dirección de Medicina Veterinaria, the Instituto Politécnico, the Instituto Pecuario, the Dirección de Economía Rural, the Escuela Nacional de Agricultura at Chapingo, the Dirección de Geografía y Meteorologia at Tacubaya, the Dirección Forestal, the Dirección de Conservación de Suelos y Agua, the Sociedad Agronómica, the Instituto de Biología, the Sociedad Alzado which is a private scientific society, the Instituto Quimico at Tacubaya, the Instituto de Medicina Tropical, the Biblioteca Nacional de México, the Banco de México and the Recursos Hydráulicos. In addition, some 25 or 30 scientists were consulted.

While the American Library in Mexico, Biblioteca Benjamín Franklin, is one of the better examples of American libraries abroad and is doing a magnificent job, its microfilm service was a great disappointment to this observer in terms of its present or potential service to individual scientists. The staff of the photographic laboratory, which is operated quite independently of the library, though in its quarters and theoretically under the director of the library, has concentrated on long run copying of archival materials, primarily for American institutions, and has not developed copying service of periodical literature for individual scholars. The prices charged for microfilms, photostats, or enlargement prints of short articles are a major deterrent to use of this service 
by individual scientists. The basis of charging apparently had no relationship to costs but rather was copied from the charges made by the Library of Congress in Washington. Thus the average article in enlargement prints would cost a scholar in Mexico 20 pesos, or more than $\$ 3.00$ as compared with $50 \phi$ to $\$$ I.OO for the same material provided by the Department of Agriculture Library in Washington, where labor costs are much higher. The fine photostat machine, with its enlarging head for making enlargements from microfilm, is practically unused, and the director of the laboratory indicated that it was unnecessary equipment. When the operation of this laboratory is taken over by the Library of Congress it appears unlikely that the present direction of emphasis will be changed since programs now are all pointed to relatively large-scale copying of archival materials rather than the provision of single copies of extracts for scholars.

If the basis of operations of this laboratory could be reoriented so as to include service to scholars at reasonable cost, it might make a real contribution to the scientific research potential. The total volume of work of the laboratory, even including its long run copying of archives, is at the rate of 60 to 70 rolls of film per year, which is only about 50,000 exposures per year. Fifty thousand exposures is about one man-months work in our photographic laboratory at Washington. Thus the total output of the laboratory, with its several standard cameras, and two microfilm cameras and a photostat camera, would not appear to justify either the staff or equipment being used at the present time for this purpose.

In view of the fact that the resources in Mexico City are probably as great as they would be in any other single location, this indicates that it would be very difficult to justify expensive camera installations in many locations in the countries surveyed. It would indicate also that microfilm and photostat service must be set up especially for service to individual scholars or they tend to become long run microfilm copying establishments. It is estimated that at the rate of pay of a staff member at Mexico City, which was reported at 100 pesos, or approximately $\$ 15.00$ per month, and the cost of the film at the rate of 45 pesos per roll, or about $\$ 6.50$ per roll, the total value of the materials and labor at our standard work load of the Department of Agriculture Library, the total cost of microfilm produced, exclusive of overhead for quarters and cost of equipment, would be only approximately $\$ 400$, or, including bookkeeping costs, at the rate charged for microfilm at the Department of Agriculture Library, something less than $\$ 500$ for this laboratory during the past year.

This subject has been treated at some length above because it indicates several very important points to this surveyor: first, that the cost of installing microfilm equipment would be very difficult to justify in terms of the probable amount of work at any given point; second, that in terms of the amount of service given to scholars and the amount of microfilm actually used by scholars, it might well be cheaper and more efficient to provide photostats; and third, that such microfilm or other photographic service as is provided must be provided through centers, as was done by Brazil and Argentina when they made use of the microfilm supplied by the Department of Agriculture Library during the war, rather than by sending microfilm to individual scholars who can't use it without considerable diffculty.

To be sure, an occasional scholar like Contreras Arias, chief of the Dirección de Geografía y Meteorología in Mexico, can 
make a homemade wall projector, using his own camera for projection or for taking pictures. But by and large the volume of use of microfilm by individuals and the feasibility of using microfilm appear to be approximately on the same level as in the U.S., and it appears that if we are to get scientific information to the scientist in a form in which he can use it, greater use could profitably be made of enlargement prints or direct photostat.

\section{Guatemala :}

The libraries visited in Guatemala include that of the Instituto Agro-pecuario Nacional, the Biblioteca Nacional de Guatemala, the Biblioteca Agrícola de la Secretaría de Agricultura, the Facultad de Ciencias Físico-matemáticas, the Facultad de Ciencias Médicas, the Facultad de Ciencias Naturales y Farmacia, the Biblioteca del Instituto Guatemalteco de Cultura and the private collection of Dr. Mario Pacheco $\mathrm{H}$.

While each of these libraries serves useful purposes there is only one collection in Guatemala of more than four or five thousand volumes in the field of agriculture or science and technology, and very few current periodicals are received in these fields. Dr. Julio Valladares, dean of the Facultad de Farmacia y Ciencias Naturales, whose library was probably the strongest in the fields considered, is very much interested in the problem of scientific communication and indicated willingness to cooperate in developing an effective program. The library of this faculty has some 20,000 volumes and receives 63 periodicals currently. This faculty has also published a number of important contributions which should be available to other libraries.

\section{El Salvador:}

The libraries visited in El Salvador include the Centro Nacional de Agronomía, the Biblioteca Nacional, the Museo Nacional, and three faculties of the University, including the Facultad de Ingeniería, the Facultad de Medicina and the Facultad de Química y Farmacia. There was no scientific library with more than 2500 volumes and pamphlets and none of the libraries except the Centro Nacional de Agronomía received more than five or 10 periodicals currently. The standard indexes were not available and the medical library, for example, receives only about 50 new titles of books and periodicals each year.

\section{HoNduras:}

In Honduras, only the Biblioteca y Archivo Nacional and the Escuela Agrícola Panamericana at Zamorano were visited. Neither of these attempts to provide research library services.

\section{Nicaragua :}

In Nicaragua only three libraries were found which contain any scientific or technical material at all. These were the Biblioteca Americana de Nicaragua, which includes in its 19,000 volumes an average small public library sampling of American technical books; the Instituto Pedagógico de Varones, which is a good high school library with a few technical books; and the Biblioteca Nacional, which contains $2 \mathrm{I}, 000$ volumes and does not have very much material in the field of technology.

\section{Costa Rica :}

The Costa Rican libraries visited were those of the Ministry of Agriculture and the Agricultural College, the Colegio San Luis at Cartago, the National University in San José, the Biblioteca Nacional, San José, the Facultad de Farmacia, the Servicio Técnico Interamericano de Cooperación Agrícola, the Centro Cultural Costarricense-Ameri- 
cano and the Museo Nacional, which includes good historical collections in entomology and several other fields.

The library of the Inter-American Institute of Agricultural Sciences is far superior at present to the collections seen elsewhere, with the possible exception of the Seccion de Investigaciones Especiales in Mexico, for the fields which that library covers. It is the only collection which contains any representation of agricultural economics and it could form a basis of a good working library for its region. The library has a considerable number of duplicates which might well be made available to other institutions in its service area. Its collection of some 7500 or 8000 volumes has been used to answer more reference questions than is common in libraries in this region.

\section{PANAMA:}

The libraries visited in Panama and the Canal Zone included the University of Panama, Summit Gardens, Ministry of Agriculture, Biblioteca Nacional and the Canal Zone Library. As a result of this visit an interesting program of cooperation between the Minister of Agriculture and the National Library is developing and that will be discussed below.

\section{Colombia :}

Colombian libraries visited included that of the Palmira Agricultural Experiment Station, which includes about I500 volumes, and receives 30 periodicals regularly; the Cali Agricultural College, with approximately 2000 volumes and 25 or 30 journals, the Facultad de Agronomía of the National University at Medellin, the Facultad de Ingeniería of the National University of Medellin, the University of Antioquia and its medical school, the University Bolivariana and the State Public Library, as well as the following libraries in Bogotá: the Ministry of Agriculture; the School of Veterinary Medicine, the Laboratorio Químico, the Facultad de Ciencias, the Facultad de Farmacia, the Facultad de Química, the Laboratorio de la Dirección de Minas y Petroleos, the library of the National Bank, of the Escuela Normal Superior, and of the Instituto Geografíco de los Andes, as well as the Biblioteca Nacional, the Facultad de Medicina and the Facultad de Farmacia of the University and the Centro Colomboamericano. In addition, discussions were held with several dozen scientists in public and private research institutions on a number of special factors in the program of scientific communication in Colombia which will be discussed below.

\section{Summary}

In general it might be said that one of the greatest problems in improving library facilities and services within the larger countries is that of dispersion of resources. For example, the National University of Colombia has nine different faculty libraries, no one of which has averaged as much as 350 new titles a year and some of which acquire as few as 40 new titles a year. The basic materials in the veterinary faculty, the medical faculty, the chemical faculty, the agricultural faculty and pharmaceutical faculty have to be duplicated to some extent so that the total number of titles available is considerably less than might be obtained under a cooperative program. Furthermore, there is no central catalog so that it is not possible readily to determine what is available in the university as a whole. The same might be pointed out with respect to the Department of Agriculture in Mexico, which has at least seven libraries, three of them in one building and each quite small and independent of the others. For example, the Biblioteca de Dirección General de Agricultura has a collection of some 6000 volumes and 
25,000 bulletins. It does not have any record of what is available in the Livestock Bureau, the Geographical-Meteorological Bureau, the Animal Industry Bureau, the Forestry Bureau or the Rural Economy Bureau. No one of these libraries receives more than 25 or 30 serial publications regularly and the general library has no funds at all for purchase of books.

One of the most interesting programs in process of development is a cooperative program between the National Library and the Ministry of Agriculture in Panama. Generally, national libraries are concerned primarily with collection and preservation of materials, but in Panama, Galileo Patiño, director of the National Library, who is well trained, has developed a very interesting and dynamic program for their library. Since the population of Panama is less than 700,000 and the National Libary is attempting to provide service to all the population, its program might be compared with that of a medium-sized public library in the United States rather than with the usual type of National Library. The library has some 60 branches and other outlets around the country and attempts to serve farm groups as well as city groups. The Ministry of Agriculture, in view of the dynamic program being carried on by the National Library, has agreed that they would be better served by the National Library than by attempting to build up a collection of their own. While this observer was in Panama the Secretary of Agriculture, Alfonso Tejeira, and Mr. Patiño reached agreement on cooperative services, with the probability that the Ministry of Agriculture will provide a bookmobile to the National Library so that the National Library may carry extension materials out to the rural groups. This appears to be a very promising experi- ment in maximum utilization of existent facilities. The cooperation which appears to be developing in Panama should result in better library service for the Ministry, for farmers, and for the public in general than could possibly be effected through the usual pattern of duplication of library facilities.

In Colombia, considerable interest was expressed in the possibility of more cooperation among scholarly institutions. Mr. Ramirez, dean of the Agricultural College at Cali, suggested that it would be desirable for the research institutions of Colombia to meet together to discuss means by which they might make greater use of their total library and bibliographic materials in Colombia. In view of the fact that this observer found many important sets of journals scattered around in different libraries, and in view of the fact that there is now no way for a scientist to determine what is available in Colombia, the possibility of such a meeting was discussed with scientists and authorities of other institutions, both from the point of view of the possibility of better utilization of what exists and from the point of view of a possible cooperative program in purchasing so as to decrease the amount of unnecessary duplication of titles and increase the total number of periodicals available in one institution or another in Colombia. This idea was received with enthusiasm at every institution visited and it would appear that if a cooperative program should be developed the research potential in Colombia would increase greatly.

Incidentally, the development of research institutions and scientific and technical educational institutions in Colombia over the last 20 years is an excellent indication of what can be achieved in a very brief time when the importance of scientific training is really appreciated. 